\title{
Try to Talk about the School Sports Teaching Research on the Effects of Environment on the Quality of Teaching
}

\author{
Xueda Yang \\ School of sports, Yan'an University, Yan'an, Shanxi Province, P.R.China, 716000 \\ E-mail:yangxueda1976@163.com
}

\begin{abstract}
With the advancement of China's school education reform, the teaching quality has once again become a hot topic of modern teaching. As part of the lifelong education system of school physical education is to promote students' physical constitution also enhance and improve the further reform. Physical enhancement is not only teaching and learning of students, only improve the quality of teaching, is likely to provide the positive energy to strengthen students' physique. Teaching quality of ascension, however, require teaching environment as a support and guarantee, without a good teaching environment, teaching quality of ascension will be constrained by many. This research USES the literature material method, logic analysis and other research methods, through the impact on the quality of hard and soft environment of physical education in teaching are discussed in this paper, to improve the teaching quality of school education and provide beneficial reference to improve the teaching environment.
\end{abstract}

Keywords-sports; The teaching environment; The quality of teaching; impact

21st century technology and the increase of modern industrial development, human survival environment is under threat and destruction, environmental problems have become the focus of global attention. Teaching environment on every link of teaching activities and students' intellectual development and learning effects, physical and mental health has important influence. As is known to all, sports teaching is one of the important teaching activities of school education, physical education teaching quality is directly related to talent training base. No sports teaching environment, organization and arrangement of the physical teaching process can be difficult to implement. Sports teaching environment is the basic condition of sports teaching activity, sports teaching activities is required for all conditions of synthesis. Obviously, the sports teaching environment relative to the teaching environment is a relatively micro teaching environment, so it cannot be free from the teaching environment and exist in isolation. Good sports teaching environment is the precondition of effective PE teaching activities, is the basic guarantee of physical education teaching activities smoothly. In the process of sports teaching, good teaching environment has positive guidance, edify, motivation and health, etc., to the student body and mind harmonious development has important significance. At present our country on the relationship between the sports teaching environment and teaching quality of research also is not very comprehensive, very system. And this article mainly from the hard and soft two sports teaching environment environmental impact on the quality of teaching as a starting point for analysis and research, to interpret the correlation between, good for improving the quality of physical education teaching.

\section{PE TEACHING WEAK ENVIRONMENT IMPACT ON THE} QUALITY OF TEACHING

"Environment create man", in which environment is people's life and subject to the influence of the objective world, visible environment on the person's influence is very big. Teaching environment is one of the part of the environment, is through the teaching effect in the process of teaching and learning of physical factors and human factors combined. Its broad sense refers to the teaching of all the social environment, such as social system, science, technology and other conditions of family and community are the teaching environment; Narrow sense refers to the school teaching activities required by the material, institutional and psychological environment, such as school

Garden, all kinds of teaching facilities, school spirit, classroom atmosphere and teacher-student relationships, etc. Sports teaching environment is the physical education teaching activities

One of the important factors, is also the important content of modern sports teaching theory research. This research embarks from the narrow sense concept of sports teaching environment can be divided into hard and soft environment. Sports teaching hardware that sports teaching environment of physical factors, including hardware sports venues, equipment, multimedia teaching measures, as the material basis of teaching and teaching security, directly affects the quality of teaching.

\section{A. The physical environment}

Physical facilities environment is the sports teaching can effectively implement foundation and material guarantee. Mainly including sports venues, stadiums,

Sports equipment and other factors, therefore, whether the teaching facilities will complete to sports teaching quality. In the school sports teaching, sports venues are mainly for the sports teaching service, however, with the continuous development of society, its function has become increasingly diverse, has set the teaching, athletic performance, entertainment, fitness, and other functions in one. So, to build a good environment for our teaching of physical education facilities and other aspects to 
provide a full range of services. Material facilities environment construction, of course, is not a short-term project, it is the financial and material resources, manpower and time and so on various aspects factor influence, will need to go through a process of development. In this process, the construction speed, improve the degree mainly depends on the school of economics and school leadership degree of understanding of it - understanding of its meaning, function and quality.

\section{B. Environmental facilities}

Teaching quality is subject to the influence of sports teaching hardware and construction. If insufficient teaching venue, equipment, the quality of teaching must be discounted, dozens of people on a basketball court or a piece of badminton field in class, to the whole teaching organization, the density of exercise and intensity will bring bad effects. Class of crowded, noisy environment will also be interested in the enthusiasm of students, enthusiasm and adverse effects, thus affecting the teaching quality. Visible, physical education teaching material establishment environment's impact on sports teaching are various and profound, especially in the current school enrollment expansion and guarantee the teaching quality in hand at the same time, must strengthen material facilities environment construction. Usually, different regions, different conditions of the school, there is a certain difference in environmental conditions, owned by the type of quantity, quality, environmental conditions are different. Schools in the environment and has its own advantages and characteristics. , for example, poor economic conditions in rural schools, although unlike city schools, good economic conditions, which has a relatively complete sports facilities, but it is rich in natural environment, sports teaching venue space is open, so, if can fully exploit and make use of their existing environmental advantage, it is possible to promote the sports teaching the environment improvement. School also can according to the budget and actual geographical environment, adjust measures to local conditions, local materials and make full use of the local environmental conditions, scientific design, ingenious arrangement of equipment facilities, especially in remote mountainous regions and rural schools, the school area, hill, trees behind the house, junk, etc., to develop multi-functional refined into ideal venues and facilities, is also a effective way to get out of sports material facilities environment construction.

\section{Application of modern information technology}

Teaching process is a multi-channel information flow project. "Teacher, a compassso to reassure also." "Тао" and "industry" is a kind of communication between teachers and students activities. And in this society with rapid development of science and technology, computer is no longer a luxury and mysterious thing, so, the multimedia teaching have quietly walked into the classroom. Multimedia diversification of modern information technology can effectively mobilize students' various senses to participate in the activities of information receiving, improve the quality of information received, at the same time, it can effectively increase per unit time of information circulation, improve the efficiency of information transfer. Teachers in the teaching by using multimedia technology such as TV, slides, video equipment, make the images, words, actions, etc. Various stimulating factors cross effect student's senses, in order to gain best effect of information transmission. On the other hand, the lack of all kinds of teaching facilities, teaching information exchange and use teaching methods will greatly restricted.

Timely with music in physical education teaching activities, can reduce the student to study the action technical feel boring, when the brain is in a state of excitement, stimulate potential and improve the action rhythm, eliminate fatigue, alleviate intense sentiment, make students master the technology in the happiness, improve skills. Such as: when we do the brain-storming, students will feel very boring, but if the match on music, can achieve very good effect. And, as the part at the end of the lesson, if deserve to go up soft and gentle music can make students eliminate fatigue, body and mind to relax. Multimedia technology into the classroom, make classroom atmosphere relaxed and happy, not only easy to arouse the students' creative thinking, still can make abstract concepts concrete, boring interesting knowledge.

Thus it can be seen that the multimedia and other modern teaching facilities to improve the teaching quality of sports has the important significance and fully pay more attention to the effect of teaching method in the teaching of science and technology, development and improvement of multimedia teaching facilities, is helpful for the improvement of the sports teaching environment and the improvement of teaching quality.

\section{SOFT ENVIRONMENT'S INFLUENCE ON THE QUALITY OF TEACHING IN THE TEACHING ENVIRONMENT}

Soft environment the humanistic factors in sports teaching environment, it includes the school traditional culture, the classroom atmosphere, the interpersonal relationship between teachers and students, course the choice of content and form, and so on, these can take great effect to promote students' emotions. Psychology thought to create emotional environment, can make the students learn knowledge in a relaxed cheerful environment, master the knowledge. Regulatory factors in the teaching environment for students to create a democratic, cooperation, explore, healthy classroom atmosphere, make students emotionally positive, free, easy and safe psychological state, thus causes the student to enter a freewheeling psychological space. Can make students study actively, active and happy, then "want me to learn" to "I want to learn".

\section{A. Teaching content choice's influence on the quality of teaching}

Teaching content can influence the students' learning motivation, and motivation is the desire, interests, needs, etc in the form of motivating students to learn a kind of subjective motivation factors, affect learning environment, process, teaching quality and result of important variables. If not interested in what teachers teach students, is teaching the red signal. Previous physical education is something to run, jump, throw those boring of track and field events, or a ball with a whistle, a lesson not only influence the appearance of the class, more make most students won't get a workout in the gym, lose interest in 
physical education. Along with the development of The Times, lessons should also unceasingly rich, the content of the survey data, can stimulate students interest in the project can be accepted by students, such as game, basketball, gymnastics, martial arts, TiJian etc, it also illustrates the project of the students like to tend to be those strong interest, has the certain performance of antagonism, and with the nature of the project. Teaching, the students should be under the guidance of teachers to mobilize their initiative, do design in teaching, teaching driven by the students. To classroom teaching content should be according to the change of teaching environment and timely adjustments to optimize, helps to improve the student's ability of sports.

The master said, "you know the less good knower, good knower than joy knower." When a person is engaged in, or like a sport, it will actively mobilize their state, make a commitment to learning, on the other hand, will be in a negative, snub the in the mind to deal with you don't love, or is forced to learn knowledge. So, want to change the traditional physical education ideas, reduce for teaching of sport technology as the main body of the teaching material system, to increase more entertaining strong and can achieve the goal of fitness project. Such as: $200 \mathrm{~m}$ than any other game, entertaining strong already, and have certain strength, reach the purpose of fitness in happiness. Traditional teaching emphasize the teachers as the leading factor, ignoring students' main body status, treat students as passive, being taught movement is just the teacher to give them increased burden, difficult to arouse students' interest in learning and motivation. To achieve from "want me to learn" to "I want to learn", the teacher must according to the actual school and curriculum reform requirements, processing and refining the content of the teaching, to arouse the enthusiasm of students, achieve the teaching goal, to improve the teaching quality.

\section{B. Relationships affect the quality of teaching}

Sports teaching, the teacher is not only restricted by their own internal factors, but also influenced by external factors associated with it. Which is one of the important external factor of human relationships, deal with all kinds of interpersonal relations, specific solutions to various adverse factors affecting the teaching, in the work and the study on leadership, colleagues of concern and support, good for improving their own quality, beneficial to the teaching work smoothly. Interpersonal relationship refers to people in social interaction, form the psychological relationship between people. Harmony between teachers and students harmonious interpersonal relationship is helpful to the improvement of students' learning interest and enthusiasm, can make students willing to accept the teachers teach knowledge, also want to close to, subtle pull close the distance between teachers and students. Good relationship between teachers and students help to improve the students' learning motivation, otherwise it will inhibit the students' interest in learning, even tired of the teacher on the class, and this requires that physical education teachers should pay attention to in the classroom teaching to establish a good image. Teachers love students, students will, in turn, to the teachers to corresponding emotional return, will be more deeply respected the teacher. "Kiss the division, and to the faith", when the student to the teacher the love reach to a certain extent, will produce the phenomenon of love me, love my dog, the teachers close to and love by love, and he taught discipline, take an interest in learning, so the harmony of the relationship between teachers and students help to smooth completion of the teaching task and the improvement of teaching quality. On the other hand, the lower the quality of teaching.

Interpersonal relationship as an important factor in sports teaching psychological environment, in the sports teaching psychological environment is both emphasis and difficulty in the study, interpersonal relation in the sports teaching mainly include the relationship between PE teachers and students and between students and students, the relationship between because their relationship is an interactive process, so he directly affects the atmosphere of the classroom teaching, teaching feedback and students' classroom participation attitude and motivation, thus affect the quality of the physical education teaching. In the process of education teaching, "teachers, the students" teaching form is more and more valued. Therefore, the relationship between teachers and students are no longer limited to the general form of teaching, also gradually extended to the care of everyday life and emotional communication, and informal communication between teachers and students to student's influence and management, and play a role in teaching of some formal exchanges between teachers and students can not reach. Because, informal communication between teachers and students is based on common interests, common thought between teachers and students such as on the basis of the conviction, so this relationship is helpful to eliminate some gap between teachers and students, is the communication between teachers and students more freedom, shorten the distance between teachers and students and the psychological resonance, which is beneficial to teaching activities smoothly.

\section{Classroom atmosphere's influence on the quality of teaching}

Sports classroom teaching atmosphere is refers to the class in the classroom teaching of produced in the process of a kind of mood and emotional state. Active classroom atmosphere conducive to sports trust and emotional communication between teachers and students, help students set up courage and confidence to overcome the difficulty, can inspire and mobilize students' learning initiative and self-consciousness. Previous PE classroom atmosphere we all have experience greatly, probably can be divided into two situations: one is a teacher too irresponsible, throwing a ball or a lesson don't organize, dissolution result in only a few sports enthusiasts can get exercise, and other students can on the sidelines, or simply return to classes to learn other math teaching content, make physical education for the privilege of a few people, contrary to the original intention of the syllabus, make physical education lost its meaning; Another is because teachers too "responsible". The whole class is in the teachers' teaching and students learning situation. Teachers out of the sense of responsibility, afraid students learn knowledge, and to take "to fill the whole hall" way of teaching, can don't go to understand the student to learn, willing to learn, can you accept. 
Classroom atmosphere is too depressive, students passion is not released. Even suppresses the students' interest in classroom content, criticized and even trained action does not reach the designated position, serious contusion of the students' self-confidence.

Gym class now although made some achievements in the curriculum reform, but there are some more serious insufficient, lively, classroom atmosphere is depressing, system had died. Coupled with traditional idea of deeply rooted, to some extent inhibited the student individuality development. Sports teaching syllabus of PE new course standard changed in the past) the sports curriculum content and arrangement of teaching hours, the framework of sports curriculum content system was reconstructed, which broaden the scope of the course. It in class on the content of the choice for a range of options, the physical education teachers in various areas, schools, teachers and students have considerable choice space and, in respect and satisfy school geographical environment difference, uniqueness, plays a special role, improve the teaching quality of primary and secondary school physical education curriculum in general but also is of great significance. Happiness just means, health is the ultimate goal. Through the teachers' choice of the content of the course and the choice of teaching methods make classroom atmosphere active, let the students in the classroom atmosphere of complete fitness purpose, finally realizes the stable improvement of teaching quality.

\section{CONCLUSION}

School is a special kind of environment, the special is that it is a simplified, purification, balance, spiritualized, people-centered environment. Of sports teaching in the environment through the analysis of the two kinds of hard and soft environment, make we awake to realize sports teaching environment and teaching scale and the number of students have dependence, especially in the current recruitment situation, the construction of sports teaching environment is particularly important. Efforts to improve physical education teaching mode, enriched the contents of the classroom and improve the enthusiasm of students. In spite of the teaching environment is restricted by many objective conditions, but can through the work, play subjective dynamic role; In the aspect of soft environment we will have a lot of activity space, as fully as possible use of the objective environment, reform and improve the existing conditions and build characteristic of sports teaching environment, respect students' personality development, physical education, can truly become a flavorful and colorful paradise, the spirit of sports teaching quality can be effectively protected.

\section{REFERENCES}

[1] Guo Shuping. The creation of teaching situation, optimization of physical education teaching $[\mathrm{J}]$. Journal of sports science research, 2001, and practices.

[2] WuZhiHui. Thinking about several theoretical issues related to teaching environment $[\mathrm{J}]$. Journal of northeast normal university, 1995, 05

[3] Liu Yang. The influence of sports teaching environment on classroom communication $[\mathrm{J}]$. Hubei sports science and technology, the 2002-01

[4] Li ping. The influence of the English teaching environment on classroom communication [J]. Cultural and educational materials, 2005, 12

[5] Ding Yi LiuXiangLin. Colleges and universities sports teaching environment micro $[\mathrm{J}]$. Journal of shenyang university, preceding 1995

[6] of prosthodontic He Xiaoyun. Optimize the teaching environment, improve the teaching quality of physical education $[\mathrm{J}]$. Journal of nanjing institute of physical education (social science edition), 2002, 12

[7] Tian Huisheng. Theory teaching environment's influence on the teaching activities [J]. Journal of education research and experiment of 1993 cutflower production potentials

[8] wei bo, Yang Jianrong. Harmonious sports environment effect on study interest [J]. Journal of health vocational education, 2012, 05 